\title{
Redefining Constructions of Sexuality and Sexual Wellbeing across Generations: Lessons from Ageing Aboriginal Women
}

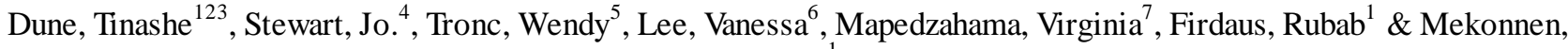 \\ Tensae $^{1}$ \\ ${ }^{1}$ School of Science and Health, Western Sydney University, Penrith NSW 2751, Australia \\ ${ }^{2}$ Centre for Health research, Western Sydney University, Penrith NSW 2751, Australia \\ ${ }^{3}$ School of Health, University of New England, Armidale NSW 2351, Australia \\ ${ }^{4}$ True, Relationships and Reproductive Health, Maroochydore Qld 4558, Australia \\ ${ }^{5}$ North Coast Aboriginal Corporation for Community Health, Birtinya Qld 4575 Australia \\ ${ }^{6}$ Faculty of Health Science, University of Sydney, NSW 2006, Australia \\ ${ }^{7}$ Faculty of Nursing and Midwifery, University of Sydney, NSW 2006, Australia
}

Received: December 5, 2017

doi:10.11114/ijsss.v6i3.3014

\begin{abstract}
Accepted: February 6, $2018 \quad$ Available online: February 9, 2018
\end{abstract}
URL: https://doi.org/10.11114/ijsss.v6i3.3014

\begin{abstract}
This study explored how Indigenous women living in Australia understand, experience and construct sexuality within contexts dominated by revealed the impact of Eurocentric conceptualisations of gender, embodiment and intimacy. This project was informed by feminist methodology and collected data using semi-structured focus groups, which naturally took on the yarning method. The discussions, held on the Sunshine Coast in Queensland, were had with women aged 42 to 73 years, across three focus groups. The women primarily constructed sexuality within Australia's history of colonisation, discrimination and prejudice against Indigenous people, the uptake of European values and their impact on Indigenous people over time and across generations. Self-esteem was a central feature across all major themes and described as integral to health constructions of sexuality and health relationships. Changes over time were characterised by the women's commitment to instilling self-esteem in following generations as well as limitations to self-esteem resulting from discrimination. Socialising future generations to display and embrace intimacy was also central to a healthy construction of sexuality. The findings from this study reinforce that learning from Indigenous women about sexuality and ageing is key to enriching the evidence-base as well as health worker and researcher capacity while reinforcing the importance of self-care among Indigenous older women. Integrating such an approach with Indigenous women has the potential to increase the effectiveness and relevance of health promotion and wellbeing programmes aimed at older Indigenous women in the present and future.
\end{abstract}

Keywords: Australia, Indigenous, women, sexuality, sexual wellbeing, ageing, cross-generational, cross-cultural

\section{Introduction}

Internationally cultures are ever-evolving and intermingling (Kirtz 2000) especially in the context of Indigenous Australia. Howe ver, Indigenous Australians live on a spectrum of at least two cultures, one which is Eurocentric and the other potentially more traditionally cultural in nature (Dockery 2010). Indigenous-specific understandings and experiences of sexuality in scholarship and practice have been occluded by the dominance of Eurocentric conceptualisations of gender, embodiment and intimacy. This cultural dominance is of particular salience to Indigenous women whose bodies have been vilified and violated within Australian's colonial history and practices (Moreton-Robinson 2003). It is within this historical and phenomenological context that Indigenous women (re)construct sexuality over time and across generations. Without an understanding of how female Indigenous Australians are in fact navigating this sociocultural space perpetuates miss-understandings as to whether or not sexuality programs aimed at improving and supporting sexual/reproductive health and wellbeing are pitched in a way to consider the Indigenous women's key concerns. This study therefore explored how indigenous women living in Australia understand, experience and construct sexuality which revealed the impact of Eurocentric values.

Considering that sexuality is such a broad term and therefore encompasses many factors, this exploratory study 
specifically sought to understand how ageing Indigenous women living in Australia constructed gender (e.g., how gender influenced understandings of sexuality), embodiment (e.g., the relevance of the body to sexuality) and intimacy (e.g., the role of intimacy in sexuality). The concentration on gender, embodiment and intimacy were chosen as the focus of discussions about contemporary sexuality as they have been cited as the factors which may influence how women relate to sexuality and sexual wellbeing (Fileborn, Thorpe et al. 2015).

This exploration can help to inform and determine the appropriateness of sexual wellbeing services/programs in Australia by presenting the views of Indigenous women ageing in Australia. This paper highlights the role of these women as significant sources of data given their experience of the evolutionary nature of constructions of sexuality that have shifted overtime and may hold different meanings across generations. This is highlighted by the evolution of the term sexuality and its relevance in Indigenous contexts.

\subsection{Understanding Sexual Wellbeing: Implications for Indigenous Australian Women}

From a Western and mainstream perspective, that which is currently dominant in Australia, sexual wellbeing is a broad term and has been defined by Durex (2015) as:

... a balance of physical, emotional and sociological factors. It's about protecting and nurturing the sexual health of both you and your partner, getting the most from your sex life and feeling confident and happy about yourself. Sexual wellbeing is a fundamental part of human wellbeing and health.

As indicated in the Durex definition a key aspect of (sexual) wellbeing and health is feeling confident and good about oneself, a key concept which the women in this study highlighted in their constructions and understandings of sexuality and sexual wellbeing (Aniekwu 2006). Even within this Western context there are many variations, inclusions, uses and meanings of the term (see for example Evans 2013, Rosengarten and Simpson 2014). For instance, sexual wellbeing and sexual health are often used interchangeably especially with regards to the psychosocial aspects of sexual health (e.g., body image, sexual self-esteem, sense of desirability, sexual satisfaction) (Evans 2013). As such, there are many ways to understand constructions of sexuality and sexual wellbeing even within Western contexts. Thus, considering that there is no one Indigenous culture - there is no singular way of understanding sexual wellbeing across these cultures.

In many traditional cultures however, 'sexuality' is understood as linked to experience(s) of womanhood, wifehood and motherhood and is reflective of various Indigenous cultural groups who have historically embraced the sanctity of women's and men's business (Campbell and Brown 2004). Within women's business aspects of sexuality are defined in relation to one's biological, sociological and community roles - which cannot and should not be pulled apart (Bell and Nkomo 1998). This reorientation in perspective (from the experience of being sexual to the experience of being a woman) highlights two knowledge gaps: 1) there is little research which has explored how Indigenous women understand and construct sexuality and more importantly, 2) there is no one, clear or universal definition of the word sexuality and/or how it relates to women and their sexual wellbeing.

According to Ward, Bryant et al. (2014) 'this is the case even with ongoing efforts in both program delivery and policy implementation aimed at addressing this disadvantage. Further these differentials have been recognised for some time, and there is little understanding of the social and behavioural factors that underpin them." Considering the emphasis placed on the social, psychological and emotional aspects of sexual wellbeing (as an indicators of sexual health) (Dune 2011, Dune, Mapedzahama et al. 2015) as mentioned above a better understanding of what constitutes sexual wellbeing from the perspective of Indigenous people is fundamental to effective sexual health promotion and service delivery over time and across generations. In order to do so, an understanding of the role of culture(s) in the construction of sexuality can be informed by theories which focus on the role of sociocultural scripting (Kiefer and Sanchez 2007).

\section{Methods}

After getting ethics approval, the project engaged into qualitative design which drew on principles of feminist methodology in which the voices of women as knowers were centred and captured within focus groups settings (Olesen 2011). Such methodology has proved successful in garnering phenomenological experiences from women of various backgrounds and was therefore the methodology of choice for this exploratory study (Landman 2006) (Dune, Mapedzahama et al. 2015, Fileborn, Thorpe et al. 2015). Data collection was conducted in March 2014 on the Sunshine Coast in Queensland and consisted of fourteen women across three focus groups. The focus groups took from two and a half hours to three hours each to complete - more time than initially predicted. This is reflective of the time taken for all members to disclose central aspects of their cultural identity (including the researchers') and the use of in-depth stories and anecdotes to embed the women's (as well as the researchers') constructions and understandings of sexuality and sexual wellbeing from their sociocultural context. This resulted in the organic utilisation of the Yarning Method developed by Bessarab and Ng'andu (2010) which supported the feminist methodology and provided a deep sense of 
rapport between the women and the researchers. In Australia, Indigenous people recognize yarning as a conversational process that involves the telling and sharing of stories and information. Yarning is culturally ascribed and cooperative; yarns follow language protocols and result in some acquisition of new meaning (Bessarab and Ng'andu 2010). As researchers, we understand that yarning is both a process and an exchange; it is reliant upon cultural protocol, relationships, and expected outcomes (Dean 2010).

In order to address the aforementioned knowledge gap we conducted focus group discussions to gain more insight. The objective of the discussions was to better understand: 1) what it is like being an Indigenous in Australia (cultural understandings of gender), 2) how the women felt about how their bodies looked, were perceived and worked over time (embodiment), and 3) how the women experienced sexually intimate relationships (intimacy, embodiment, sexual function/performance, gender) including their role in sexually intimate relationships and how has their role, and its related expectations, had changed over time and across generations.

\subsection{Data Analysis}

The data were thematically analysed by identifying topics and substantive categories within participants' accounts in relation to the study's objectives. In addition, Quirkos was used to ascertain topical responses and emergent substantive categories, coding particularly for word repetition, direct and emotional statements and discourse markers including intensifiers, connectives and evaluative clauses. Quirkos is a qualitative analysis software for coding and exploring text with graphical visualisation. Coding was done independently by author (RF) who then reached on the consensus after discussing with the principle author (TD).

\subsection{Recruitment and Research Partnerships}

Participants were recruited via plain-English advertisements sent to women via a number of organisational mailing lists. These organisations included Family Planning Queensland (FPQ) and the North Coast Indigenous Corporation for Community Health (NCACCH). Convenience from personal contacts and snowballing sampling were also used to recruit participants. The academic researcher (TD) took on a supportive, versus lead, role in the development of the recruitment process, the selection of times (and being flexible about when focus groups began and ended) as well as the selection of where focus groups were held. In addition, all documents (Participant Information Sheet and Consent Forms) and data collection tools (demographic questions and focus group topic guide) were developed and finalised in collaboration with the organisation Research Officers from FPQ and NCACCH prior to their use in the focus groups. Further, the women were encouraged to ask questions (which they did) within the focus groups, of each other and the academic researcher, as well as the organisation Research Officers. As indicated by Bessarab and Ng'andu (2010) the yarning methods' "strength is in the cultural security that it creates for Indigenous people participating in research. Yarning is a process that cuts across the formality of identity as a researcher... both are learners in the process".

\subsection{Sample}

Recruitment resulted in a sample of eleven women, between the ages of 42 and 73 . Prior to the beginning of the focus groups the women were asked to answer questions pertaining to their socio-demographic characteristics and to choose a pseudonym to ensure their anonymity in the dissemination of the data. The socio-demographic questions indicate that all of the women identified as Indigenous and originated from a variety of mobs across Australia. All but one woman had children and the majority had three or more children. The majority of the women had a number of grandchildren and one woman indicated her great grand and step great grandchildren as well. The participants' marital status was mixed with three married, four single, two in de facto relationships, one divorced and one widowed. Considering the age of the women who participated in the research a majority had completed menopause with only a couple going through menopause at the time of the focus groups. Their highest level of education was mixed with some not having finished primary and/or secondary school and others who had completed tertiary studies (e.g., diploma, certificate, undergraduate degree). The majority of the women in this research were employed or engaged in an occupation and revolved around the bio-psychosocial aspects of health and wellbeing with many have specialising in Indigenous health care.

\section{Results}

The data from the focus groups produced rich insights into how Indigenous Australian women understand and construct sexuality from their perspective. The following section provides examples of how the women defined sexuality, the sexual role their bodies played in the context of Indigeneity and how intimacy was viewed or experienced over time, across cultures and between generations.

\subsection{Constructions of Sexuality}

In order to explore how the women understood and constructed sexuality they were asked what the concept meant to them. Their responses included Definitions of Sexuality, Intergenerational Socialisation, Sexual Behaviour and Sexual Satisfaction and Pleasure. 


\subsection{Definitions of Sexuality}

For the majority of the women sexuality was initially defined in the context of sexual diversity (e.g., sexual orientation, gender expression and gender identity).

Well sexuality, if a gay guy comes over with a lot of female characteristics, so that makes him the female, to me. So the role you play as well? Yes. The sexual role that you play? (Maroochydore) See I'm thinking sexuality... as gay and lesbian... (Nambour)

Considering that the breadth and depth of what sexuality is and encompasses is so vast and varied, the women seemed to default to ways of defining sexuality in ways that could be externally identifiable. In this instance, the women described sexuality in ways which could be named or labelled. This initial default is not atypical or necessarily prejudicial. According to Johnson, Gill et al. (2007) people are able to accurately judge the sexual orientation of others by examining another's body shape and motion. As such, this way of defining others' sexuality is perhaps an easy way to understand what sexuality may mean to that indi vidual. With that in mind these aspects of sexuality were described with acceptance and inclusivity and with the belief that sexual diversity was a normal human variation.

\section{[Mother] was ok for any of us to be lesbians or, cause she hanged around a lot of gay people so she} understood that that was you know, it was just normal for us. (Nambour)

Acceptance of sexual diversity within Indigenous-led health and wellbeing organisation which provide LGBTIQ-friendly services and training (Mooney and Sariago 2015) reinforces the women's perspectives. Some women also noted that sexual diversity was fluid and perceived as something which is individually defined.

So you're male or female. I guess sexuality is expressing yourself in an intimate way and that is an individual thing and it's a very personal thing. (Maroochydore)

But some people are, there's both, there's bisexuals. That's right and that's what I mean sexuality is an individual thing, it's very personal and it's veryfluid. (Maroochydore)

The previous quotes indicate the women's expansion and fluidity of both the term sexuality and sexual diversity to include aspects of an individual's sex, gender, sexual orientation and individuality. This broader definition of sexuality therefore begins to mirror the more recent and Western definitions of sexuality (Dune 2014). Other contexts in which sexuality was defined included abuse and coercion and the impact this may have on how an individual constructs, understands and experiences sexuality.

Or people who have been sexually abused...the way that they would understand it would be totally different. And it depends on who is sexually abused and if it was a family member. (Nambour)

The inclusion of sexual experience demonstrates the women's varied perspectives on sexuality as well as their astute ability to see it from a number of angles. To reinforce this perspective research indicates that women who have been sexually abused experience significant changes in their sexual health and sexual wellbeing outcomes long into adulthood and older age (Meston, Rellini et al. 2006, Berthelot, Godbout et al. 2014). With regards to sexual and reproductive health the women also defined sexuality in the context of unplanned teen pregnancy.

\section{Like you go and screw that boy you're gonna get pregnant so it was a big emphasis. (Maroochydore)}

Although it may have initially seemed that the defining characteristics of sexuality were narrow, the women expounded on those definitions to include a wide range of understandings. These understanding represent the inclusion of biological, psychological, social and health related aspects of sexuality.

\subsection{Intergenerational Socialisation}

Constructions of sexuality were also influenced by the ways in which the women had been socialised as children and young women about what sexuality was and how it was dealt with. In particular, the prevention of unplanned teen pregnancy was discussed in relation to the social ramifications if such a situation occurred.

..... if you go and screw that boy and get pregnant look out...If I got pregnant I would never go home... If you're old enough to open your legs, and you're old enough to get pregnant, you're old enough to bring that kid up... (Maroochydore)

I was the oldest girl and I was having period problems and I had to go on the pill at 15. My father cracked it, "Ah she's gonna go have sex, you're just giving her the reason... Permission ...(Nambour)

These perspectives are no different to the messages addressed to young women about avoiding unplanned pregnancy and may reflect universality when it comes to defining and constructing women's sexuality in general (Dune and Mapedzahama under review). Even with clear restrictions around teen and unplanned pregnancy there were exceptions to the rule. When one family was faced with being separated from their 
offspring via adoption their response was adapted and may be linked to historical events like the Stolen Generations.

...one of the sisters did get pregnant and she was young, she was underage and my parents just picked her up and nurtured her like a baby. She got all the support from everyone. I was up at the house and my dad came up to me and said the boy's parents' want to adopt the baby out". Dad said "no way we're not adopting any of our babies out...we 're not giving any of our babies away". (Nambour)

The resistance to adoption for these women and their families may have been borne not only of the desire to keep their families together but also to resist the dissolution of their heritage and culture - an outcome forced upon these women and their relatives during the Stolen Generations. The Stolen Generations was a program which removed Indigenous children from their families and aimed to reform them in Christian missions before relocating some children to the homes of settler Australians. The Stolen Generations are characterised by a paternalistic strategy under the laws and policies of Australian Federal and State Governments during a large part of the 20th Century and was based on systemic racism and discrimination (Dudgeon and Hirvonen 2014). Some of the women noted ongoing racism and discrimination has impeded positive and developmental intergenerational socialisation about sexuality which they felt they should have had.

That stuff come about then when our aunties and grandmothers and that would prepare us for adulthood and being you know beautiful young women. We didn't have that. All we had was oppressional "She's just a black gin", “Just a little Abo, don't worry about her". (Nambour)

As a result of this cultural vilification and disconnection most women indicated that they were denied culturally prescribed ceremony and training as part of rites of passage to womanhood. This is a common outcome of colonisation where the traditional beliefs and practices of Indigenous peoples are devalued and discouraged in favour of the colonisers' sociocultural paradigms and behaviours (Waters 2013, Benzies 2014). As a result, many of the women explained that they enacted 'womanhood' as prescribed by contemporary/Western culture.
...you do your role. You become a Mum, you get married. Yeah, there's sex involved but sexuality and beauty and all that sort of stuff is just never part of who we were. It was never instilled in us and I think that's because of the oppression of our mothers and our grandmothers and our great grandmothers. And um, whereas previously, in traditional times young women went through rites of passage and ceremonial stuff... (Nambour)

With positive and developmental intergenerational socialisation about sexuality stunted, the majority of women explained that sexuality was mired in silence and taboo.
Participant: People didn't talk about those things and least of all Aboriginal people. Something that was taboo I suppose.

Moderator: Why is it taboo?

Participant 1: Because they weren't told themselves. They weren't educated. There was nothing like that when I was in my teens.

Moderator: Why not?

Participant 1: It just didn't get discussed in my household with my sister and mum. So no-one said anything.

Moderator: No. So how did you all learn aboutperiods?

Participant 1: It just happened.

Participant 2: We weren't told. (Gympie)

The silence surrounding issues of sexuality may have been the result of a long-standing and ongoing colonial influence on constructions and understandings of sexuality in Australia (Dune, Mapedzahama et al. 2015). With their own cultures, and therefore messages about sexuality, having been usurped by Christian doctrine and the devaluation of Indigenous people the women seemed to have been left with few avenues for guidance or support for their psychosociosexual development. Considering this context and the limitations to receiving information about sexuality from their family the women indicated that in adolescence they began to construct their understanding of sexuality using other sources.

I talked to my friends that were a few years older than me...I'm a great reader and I'll pick up anything that talks about what you need to know about. (Gympie)

The agency in developing their own constructions and understandings of sexuality in the absence of sociocultural frameworks defined by Indigenous cultural heritage demonstrates the women's resourcefulness and desire to develop 
their own understandings. As noted by Jones and Biddlecom (2011) who studied young people's use of the internet as a means of filling sex education gaps, young people want to know about sexuality and will find ways to get the answers they seek. However, the experience of having to seek information for oneself was not the same for all the women. For instance, one woman had a very different experience to the others and was provided with in-depth and comprehensive intergenerational socialisation which influenced her construction of sexuality, albeit with clear boundaries.

If you knew my mother, then you'd completely understand. My mother worked for the health department and it was quite common for her even with five children... to go away for a conference and come back with heaps of condoms and all that so sexuality, sex, was quite open in my family and mum and dad were very... But if you ever come home and you were pregnant, before you got married, God help us. Anyone else could do it but if we did it, any of us kids, we were dead meat and we knew that. (Nambour)

Whether intergenerational socialisation about sexuality was undermined or embraced all the women wanted positive, open and beneficial constructions of sexuality to be shared with future generations.
So don't ever think that your girls, your nieces, your granddaughters have got the basics because they might not...Just be aware. At least listen out if you hear kids say something and you think "that doesn't sound right"... When my daughters were younger I used to borrow books from the library and they go "we're not reading that". Yeah. My mother did the same. Yeah. And I'd just leave them there and not say a thing. Every now and then you'd see them picking them up and having a bit of a look. (Maroochydore)

The actions these women have taken towards breaking the cycle of silence between generations with regards to discussing sexuality is clearly seen from the women's narratives. The desire for things to be different for the next generation also demonstrates their recognition of the importance of sexuality to human de velopment. The women also noted that across generations there has been a change in the ways in which sexuality is constructed, discussed and disseminated.

These days everything is on the table. You hear about it at school, you hear about it in the community, you read it in the books, you see it on the television, you see it on the internet. It's all here now. (Maroochydore)

The reasons given for supporting both young people's and community awareness about sexuality reinforces the women's roles as mediums for this information and may resemble how this information may have been transmitted before colonisation. The ways in which the women discuss these issues also parallel the social, collaborative and therapeutic aspects of the yarning method described by Bessarab and $\mathrm{Ng}^{\prime}$ andu (2010). This change in how sexuality was discussed between generations also demonstrates the women's desire to foster agency, responsibility and accountability in future generations.

I say to my kids now "you're old enough and ugly enough to do what you want to do but the decision is yours and if you get to the fork in the road and you go down this way and it was the right decision that's fine.... if it was the wrong one you back up and start again". (Maroochydore)

In order to foster responsibility within the next generation in support of positive sexual health and wellbeing decision-making the women felt that having a solid sense of one's own worth was necessary (see also Evans 2013). Specifically, many of the women explained that the de velopment of a healthy relationship with oneself started with self-respect and self-esteem which was central to healthy constructions and experiences of sexuality.
I think the main thing would be to actually have a healthy relationship, view of themselves to love themselves and to believe in themselves and I think that is a good start and I think that theyneed to maintain that and to hang around people that are going to believe and reinforce that. And if they don't maybe choose your friends a bit more wisely. But that believing in themselves and loving themselves, a healthy relationship with themselves...they would make more positive choices for themselves regards to future relationships. (Maroochydore)

This empowering view of the construction of self in the context of sexuality provides insight into how concepts of self-worth translate into feeling sexy or attractive. According to many of the women "being desirable, attractive [and] confident" was contingent on having self-esteem. However, for the majority of women "it takes a long time to get there" (Nambour). Considering the women's negative experiences related to having been an Indigenous young woman between the 1940s and 1980s in Australia, the development of a positive sense of oneself is understandably strained. In his discussion of culture and wellbeing amongst Indigenous Australians Dockery (2010) notes that people trying to 'live between two cultures' may experience a loss of self-esteem indicative of the isolation, confusion and the feelings of loss of control when connections to culture are lost. 


\subsection{Sexual Behaviour}

Sexual behaviour was also a key aspect of how these women constructed sexuality albeit within the context of what seemed to be obligation.

W4: My husband makes me feel [sexual]. Idon't want it. I say 'give us a hug darling and a kiss.' I'm affectionate, that's what. I like touch...

Moderator: So you'd rather intimacy?

W4: ... and kissing and everything like that. I'll say 'give me a hug I'm going' or whatever but you know what he does? He goes for the genitalia but I don't want it.

All: [Laughing] (Nambour)

It seems to be, I'm at that stage now, where I still enjoy it and we still have sex but sometimes you don't want it and they just want it... They always want it... So then you have to. Why? Men are always ready. Yes, always ready. They're always thinking about it. It's always on their minds... And women aren't? Women aren't. (Nambour)

Sexual behaviour in the context of marital obligation may have had a negative impact on the agency and sense of worth they aimed to instill in the next generation. These narratives whilst demonstrating inequality between gender sex roles and behaviours may be less a note on culture and more a testament of the generational frameworks of the 1940s and 1950s in which women were not sexual agents (Chesters 2012). Not having agency within a sexual interaction was again described as having an influence on how women may re/construct their sexuality.
And it depends on who is sexually abused and if it was a family member. And how bad it is. Because some girls have been sexually abused and they have sex all the time and go into prostitution. And you have other ones that have been sexually abused that can never have a relationship with a man because they become so scared of people. So it depends on what happened. There is no one size fits all. (Nambour)

The ways in which sexuality is constructed and therefore experienced has had significant implications for the satisfaction and pleasure these women reaped from their intimate interactions with others (see for instance Dune 2012).

\subsection{Sexual Satisfaction and Pleasure}

Whilst all the women agreed that women and men's sexual satisfaction and pleasure was equally important it was clear that how this was achieved and experienced varied. As noted in the previous section most of the women indicated that men were more focused on sexual intercourse while the women were more focused on intimacy. However, some women noted changes to this dichotomy as relationships matured.

\section{Now we like to go out to dinner on our own. We go for walks, we still hold hands. And that's more satisfying? Yeah! Just being about to talk about your day. (Nambour)}

This change in the ways satisfaction within sexual relationships is defined is similar corroborates research on the ways in which sexual satisfaction evolves over time. For instance, Chao, Lin et al. (2011) explain that in acknowledging that sex is a major aspect of the human experience sexual satisfaction does not have to decrease with the increase of age. Instead, the means through which sexual satisfaction is sought (e.g., sexual intercourse) generally broadens and focuses on other behaviours like "touching, caressing, fantasy, masturbation, physical closeness with a partner, and so on; therefore, the evaluation of sexual satisfaction comprises many different levels" (Chao, Lin et al. 2011). For others changing physiology transformed the way the women reflected on sexual satisfaction and pleasure (Ratner, Erekson et al. 2011).

I liked it better when I was younger...I suppose going through menopause. But when I was younger I
used to quite like it. I enjoyed it. Especially when you are in your 20s. (Gympie)

These narratives highlight the redefining of sexuality as time goes on and between generations. For example, differences in the way sexual satisfaction was experienced between generations was also discussed in the context of the women's conversations with younger women.

W5: And I'm saying "what do you mean benefits? What are you talking about?" She said "Mum just friends with benefits and I'm going "What?!"

Moderator: Well what benefits do they get?

W5: It's just sex. No relationship.

All: Ohhhhhhh! 
W5: No ties. No commitment. I'll have a friend with a bit of sex on the side. And that really threw me... and she said "come on mum, get with it, friends with benefits". So that threw me for a while but I think, for young girls compared to their mothers, our kids are so confident around sex and confident around other things. Everything. And it's good to see because when I grew up I was quite reserved and to see our girls out there so, about sex, what about sex we were useless. (Nambour)

A friends with benefits arrangement seemed like a new and different way of constructing sexual relations and satisfaction. It may be that their surprise was based on the agency and independence that sexual partners in such an arrangement may experience or that sex could be seemingly separated from long-term intimate relationships. Again this generational difference seems to have little to do with Indigenous cultural perspectives per se and more with the generation in which these women grew up. However, constructing sexuality as a means to reap one's own sexual satisfaction was not completely new to the women. One woman described how sexual satisfaction and pleasure manifested in a similar way to a "friends with benefits" approach.

\section{I think a lot of women; theyjust want someone to love 'em. They'll step out of one bad relationship into another without trying to take a deep breath. Whereas some of us like, I've been on my own since my daughter was, she's 19 now. And I don't worry about. Yeah I go out and pick up a dude and flick him but I never take him home. You get what you need and move on. (Nambour)}

Although this woman may have experienced sexual satisfaction from casual sexual encounters it may have been both a means of agency over her sexual desires and perhaps to avoid the possibility of becoming deeply involved and entering another bad relationship. Of course there may be many reasons for this way of engaging with one's sexuality.

\subsection{Embodiment in the Context of Indigeneity}

Throughout the findings and themes a core thread of personal esteem strongly influenced how the women constructed, understood and experienced sexuality. This was particularly true for embodiment and how the women related to their bodies in the context of being Indigenous. Themes include Self-esteem, Body Image and Sexual-esteem.

\subsection{Self-esteem}

All of the women "loved" being Indigenous and were very proud in that respect. However, their ability to feel positive about their bodies was impeded by constructions of Indigeneity which resulted in vilification, abuse and the exclusion of Indigenous people.

Moderator: When you were younger did you feel attractive? Now do you feel attractive?

All: No, no, no! Never!

W1: Many challenges were thrown at us. 'You're a Black fella get over there you're not mixing with $u s^{\prime} \ldots$

All: [Agreeing]

W2: In [place, place] you would just get called a little Abo and you couldn't be around the White kids, you couldn't sit where the White kids sat you couldn't play with the White kids even though your friends were White. So you were made to feel unattractive?

\section{All: [Agreeing]}

Moderator: What does that mean for you as you aged?

W1: I think it affects your self-esteem for the rest of your life.

W2: It does wear down your self-esteem. My life would have been totally different and I know that for a fact had I had self-worth and self-esteem. (Gympie)

Up to this point many of the women's experiences and perspectives could be explained in the context of their age or generation. However, sociocultural constructions of what it means to exist in an Indigenous or Black body highlight a purely cultural experience. The women's understandings of their bodies and consequently manifestations of self-esteem and self-worth were strongly influenced by racism which fed systemic prejudice and discrimination. According to Larson, Gillies et al. (2007) ongoing experiences of racism have far reaching health impacts and can change how individuals understand themselves and others. Considering sexual script theory which explains the role of public, interpersonal and private messages about people, behaviour and thoughts (Simon and Gagnon 2011) the impact of discrimination enacted upon one's racial or cultural group can result in difficulties in all intimate relationships. Similar experiences were also noted by the women in Nambour:

$$
\text { W2: Yes, racism... }
$$


W1: And also when your Mum went out with a White fella he didn't respect your Aboriginality.

Moderator: What do you mean?

W1: Like he would... he was a right bastard. And he used to beat you down...

All: [Agreeing]

W1: Yeah! 'You little bastards, get away'.

Moderator: Really?!

All: Yeah!

Moderator: But he was dating your mother.

All: Yeah! (Nambour)

The consistency of such experiences of discrimination imbued all aspects of the women's lives and influenced not only how they related to themselves but also how previous generations related to them. In Maroochydore the transgenerational trauma that resulted was clear:

But when you come from a mission and you've got White missionaries dictating to you so you know you're Black. You've been ostracised all your life. So our lot and our mothers grew up with that and they found someone to love 'em. Cause at the end of the day the missionaries beat 'em. Like they weren 't allowed to marry and the missionaries told them who they're going to marry. So my Mum was 13 when she was forced to marry, she was a kid. So of course that marriage broke down because he's thinking 'Hey this is good' and he's going out with all her other friends and the marriage broke down. So she was supposed to marry a bloke from Alice Springs, another Aboriginal fella. So it wasn't like how me and you go out there and find love and all that bliss. Nah! They were forced to marry so then that broke down and then a lot of those men left those women with all the kids. They shunned the responsibility. So then when they had a White fella love them for who they are they accepted that. You gotta remember, back in that day when our Mum's were growing up there was no pension so they had to hook up with a fella to support 'em. To bring us kids up. So within that that racial torment just kept going, spiralling out of control. (Maroochydore)

Given the situation this woman describes Indigenous women had little choice in both the construction and use of their bodies. This narrative indicates that during the Stolen Generations their mothers' bodies were allocated to the Missions and then to husbands chosen for them (or whom they chose under duress) and then to their children. As such, the worth of an Indigenous woman's body was rarely constructed from a point of gender, social, cultural and/or economic equality (Dudgeon and Hirvonen 2014). For subsequent generations prejudice against the Indigenous body and what it is supposed to look like also came through in the women's narratives.

I've got two daughters and when people find out they're Aboriginal they say 'Oh, they're Aboriginal!', like it's a big surprise. 'Oh they're Aboriginal and they're beautiful girls'. Like it's a big surprise! What will that do to their self-esteem? (Nambour)

Although the experience of racism encountered by the women or their mothers is no longer prevalent many argue that contemporary racism has simply changed in form (Paradies and Cunningham 2009, Cunningham and Paradies 2012). Even so the women felt that younger generations of Aboriginal people did not experience the same extent of discrimination. The women perceived that this made most youth better able to demonstrate and embody positive self-esteem.

Even our boys are in selfies. Our boys would never be out there, you know my grandsons are taking selfies and they're doing law degrees and you stop and think. Our boys wouldn't do that because, "shame!!!” You know! Or "get that camera away!" My boys are saying "where is the camera?" And you should see these girls they're takin' selfies. My husband's actually like that. He's very camera shy. (Nambour)

W4:our young children today are quite different and so confident and they know they're beautiful.

Moderator: Where do they get it from?

W4: Us. From us. They get it from us. And they go to school and they say "I'm beautiful" and Igo "yup". "You sure are!” You know! And that's true! My grandkids say "Nan, I'm beautiful". Yeah! (Nambour)

While the women themselves may not have high levels of self-esteem as a result of discrimination their support of the next generation in fostering self-esteem, as discussed in the previous theme on Intergenerational Socialisation, is 
acknowledged in their narratives. This acknowledgement reinforces research by Orth and Robins (2014) who reviewed longitudinal studies on self-esteem and note that self-esteem can be influenced by social support and peaks in adolescence and decreases in older age particularly for culturally and linguistically diverse people. So while the women perceived most young Indigenous people to embody and display high levels of self-esteem, they expressed that there is still much work to be done in order to ensure the both family and community.

But there are still a lot of our young people that aren't. That are very shy and reserved. That are very shamed. Very embarrassed. And where does that come from? And it comes from there are still things happening in our community and in our families that need to be fixed. (Gympie)

Considering that both self-esteem and the way in which their bodies were constructed in the context of Indigeneity especially during their youth the women had much to say about their ageing bodies.

3.8 Body Image

For all the women experiences of discrimination continued to manifest in their lives and changed the ways in which they perceived of their bodies and of those who were attracted to them. This was particularly evident in the context of receiving compliments. The women in Nambour said:

W1: Yes! So you'veleft the house feeling great and as soon as you go out...

W1: And then someone gives you a compliment....

W2: And sometimes you know we carry weight as a protection...

W1: Yeah!

W2: To keep people at a distance.

W1: Yeah!

W2: That's our protection, us Aboriginal women.

W1: If you've gone through a really bad relationship...traumatic times, we build this big barrier. And if some fella likes you, you say 'get out you dirty dog I don't know what you're up to, keep your distance.' You've got that barrier and you're not letting that wall down because...This fella wanted to take me out and he said 'I wish you'd let your wall down'.

\section{All: Yeah (Nambour)}

The use of extra weight may have been a means to protect the women from the male gaze assuming that a majority of heterosexual men may not prefer a fuller figured woman. As a result of this assumption the women were surprised when men showed interest and the women in turn responded with distrust of the men's' motives. The concept of using weight as a protection from the potential of bad relationships obviously has significant implications for Indigenous women's health outcomes and indicates the salience and impact of psychological distress in strategies to maintain resilience and control. Although extra weight was noted as an issue by all the women many were quite positive and accepting of their bodies.

What you see is what you get and I think I'm beautiful. Doesn't matter what other people think. (Gympie)

Well that's what you look like when you get older...you do lose that muscle tone. I've got stomach now that I never had...I've never had a problem but then I think I've always been conscious. Even now I'm conscious. Always conscious of looking after our health too. (Gympie)

The positive and conscientious attitudes several women had towards their bodies was fostered despite limited images of Indigenous women in mainstream media.

\section{Aboriginal women are sexy! They're not portrayed enough in the media Idon't think... They're not} portrayed full stop. Indigenous women are not there. (Maroochydore)

In line with sexual script theory the lack of representation of Indigenous women in public spheres reinforces the exclusion of Indigenous women from interpersonal relationships in which they feel valued, worthy, attractive and sexy (e.g., private sexual scripts).

\subsection{Sexual Esteem}

Constructing a sense of internal attractiveness or sexiness was complicated for these women as their sexual esteem was negatively affected by archaic and/or misogynistic constructions of sexuality which were then passed across generations. 
You know a lot of Aboriginal women were, in their teens you know, very badly treated and raped and abused and assaulted so that's why we don't, we don't think about ourselves and sexuality. It's not something we discuss. It's not something we feel. (Nambour)

Again the objectifying use of Indigenous women's bodies during an openly prejudicial and discriminatory period of Australia's history has clearly dictated how the women feel about themselves and their bodies (Baxi 2014). The idea that sexual abuse was the outcome of sexual esteem seems contradictory and absolutely absurd in a contemporary Australian context. Whilst times may have changed these women carry these experiences across their lifetime. Such an experience is again linked to existing in an Indigenous body and clearly the result of prejudice against Aboriginal people. Given these intense experiences one wonders of the effect on the women's interpersonal interactions and particularly experiences of intimacy.

\subsection{Intimacy and Its Manifestations}

Intimacy was a very important aspect in the women's constructions of sexuality and the ways in which it manifested in their lives and relationships. There were notable changes over time and across generations as captured in the following themes: The Parameters of Intimacy, Maturation and Displays of Affection .

\subsubsection{The Parameters of Intimacy}

Intimacy included a range of factors such as "trust, respect, love, feelings, emotional connection, openness", "being close...connection" and "putting yourself in a vulnerable position" (Maroochydore). All the women agreed that these aspects of sexual relationships were most important. However, several factors influenced both the opportunity and extent to which the women could engage. One woman discussed how long it took to decompress after a long day and the way it affected opportunities for intimacy.

\section{So when it comes to intimacy you can 't just snap and do it you need a whole space of time to just decompress from work, decompress from stress. (Nambour)}

All the women agreed with this statement. Considering their many roles, discussed earlier, it is not surprising that the opportunities for intimacy were limited. Other factors also limited engagement with intimacy. For instance, several of the women had previously had negative experiences with regards to intimate and sexual relationships and were wary of engaging in relationships and had developed strategies to protect themselves.

\section{W2: It's hard to get involved again when you've had bad relationships. You just want to go out and have sex and come back. Don't get wrapped up in things again.}

W3: You can say what you want. I'd be quite happy if I had someone I could ring up and have fun in bed then tell them "piss off and let me get on with my life". (Nambour)

This narrative reiterates the potential satisfaction which can be experienced from a "friends-with-benefits" scenario discussed earlier. However, avoiding intimacy as a strategy to avoid entering a bad relationship in a way demonstrates the women's resilience and mirrors the experiences of many women who have come out of such relationships. It should be understood though that explains the impact of a bad relationship have ongoing repercussions which Bass and Davis (2002) explain can take a lifetime to heal.

\subsubsection{Maturation}

As the women matured their views on sexual and intimate relationships changed and so too did the role of intimacy in their sexual lives.

I was married for 25 years and then I had a relationship for a long time. We were too different and when people say that opposites attract there's just no way. I love male company but I like my own company. (Gympie)

Now that we're older and have the confidence within ourselves and we know who we are we don't need to have [men] there. (Nambour)

Here age comes with independence and a reclaiming of the women's individual identities separate to men or objectified constructions of their bodies. This shift away from dependence upon intimate relationships was also demonstrated in the narratives of ageing Australian women with regards to gender, embodiment and intimacy (Fileborn, Thorpe et al. 2015). With this in mind some women explained that ageing meant sexual freedom as "you don't have to lock the door anymore" (Gympie). For others intimate relationships also matured with a shift from sexual intimacy to more emotional intimacy.

\section{"It's petering off but that side of it's there. There's still the side of the love and the companionship and stuff like that. (Gympie)}

Although incidence of sexual intercourse may have reduced intimate playfulness and seduction did not. 
W1: Yeah, if I was to tease J I'll just come up to his shoulder and I'll say "don't you just wish I could throw you onto the bed like I used to?"

\section{All: [Laughing] (Nambour)}

This maturation process in the manifestations of intimacy as people age is not particular to these Indigenous women. In fact studies from around the world highlight that as relationships and people age the ways in which they display affection for intimate partners evolves (Lindau, Schumm et al. 2007, Rheaume and Mitty 2008, Kalra, Subramanyam et al. 2011, Sandberg 2013).

\subsubsection{Displays of Affection}

The women had a holistic view on the many ways intimacy could be displayed which extended beyond sexual intimacy and sexual relationships.
So intimacy isn 't just about the things you do, it's about how you actually interact with people, so I love you or you give a hug...the touch is very important. It doesn't matter whether it's your family or you're going to a hospital to see a friend, holding someone's hand and the warmth of that is everything or you put your arm around that person. If they're a stranger that you don'treally know them, I think that's really important that people know that this person cares. (Gympie)

This perspective may have been informed by the women's engagement with patients within the health care system in which many of them worked. In such a setting intimacy between patient and caregiver is essential to assisting in recovery and securing trust (Stavropoulou, Kaba et al. 2012). As such, the women may have developed an understanding of intimacy which went beyond the boundaries of sexuality and spoke to the many roles they play in their communities and families which require a broader understanding and expression of intimacy. The women also noted that this holistic view of intimacy is an important feature for future generations who may not have been brought up to be affectionate and may therefore struggle to foster intimacy with intimate partners.
If you've got the right person and have that real love and affection for each other it's how you love each other and you want to be together. You want to be cuddled. You want to have hugs and have that intimate relationship. If you hate someone it's a waste of time. I think it's important to treat people as you like to be treated regardless. (Gympie)

Being taught to be affectionate by those of previous generations had not happened for all the women even though affection was noted as central to survival.

\section{W2: When you're in the orphanage you don't see affection.}

W1: And when you're brought up in a single family all mum's doing is trying to probably worry about where the nextfeed's coming from.

\section{W3: Some people aren't brought up with affection especially people in the country. \\ Moderator: So if you weren't brought up with affection why is it important for you to do that now?}

W4: I think it's very hard for people not to survive without the love, giving the love and the one good thing that I'm very grateful for, we were brought up in a Christian atmosphere and I think that has stuck with me. (Gympie)

Interestingly the foundations of Christianity which supported the enactment of discriminatory practices against Indigenous women in ways which negatively impacted a range of sexual wellbeing outcomes also seemed to be the foundation upon which the development of healthy intimate relationships could grow. This is one of many examples, as described above, of these women's ability to redefine constructions of sexuality and sexual wellbeing both over time and across generations.

\section{Discussion}

The women in this study shared experiences of ageing from the specific cultural perspective of Aboriginal women. More importantly, these women leave us with important lessons about how persistent, objectifying and/or discriminatory constructions of Indigenous women's sexuality, bodies and relationships are being consciously and agentically reshaped to support future generations.

Conceptually this research offers support for diverse and various understandings of sexuality as influenced by culture. As such, the recent construction of sexuality in Western contexts or the term sexuality cannot be used without scrutiny. Doing so would assume a generic and global interpretation of the term which may in fact exclude or demean other ways of engaging with the concept. Much like global feminisms, sexuality, which is influenced by social and cultural contexts, should be explored as varying and dynamic especially within multicultural countries like Australia. From this however a 
key issue arises. Considering the recent nature of the term sexuality it is perhaps likely that ageing women from various backgrounds living in Australia may not define or understand sexuality in the way that it is has been constructed in the last 30 to 40 years. As such, constructions of sexuality may equally be the result of one's generational and one's cultural experiences and understandings.

The findings from this exploratory study also corroborate the validity of sexual script theory which purports that sexuality is constructed from public, interpersonal and private scripts. This is noted from the fact that culture, a product of public, interpersonal and private social scripts had such a great influence on these women's understanding of sexuality; from how they were constructed and treated in public especially with regard to racism, prejudice and discrimination to how they experienced their bodies and intimacy. As such, future research would benefit from the maintenance of sexual script theory at its foundation and/or analysis to better understand the role and influence of cross-cultural and cross-generational sexual scripts on the next generation of Indigenous women. Doing so may highlight the salience and relevance of Western, or other, concepts of sexuality for Indigenous Australian women over time.

Considering the breadth and depth of the findings it is clear that the women had much to say on their understandings and constructions of sexuality and what this meant for their experiences as Indigenous women within the context of colonial history. As with many exploratory topics about women, their health and their wellbeing, silence and lack of opportunity to give voice to integral parts of these foundational experiences for both themselves and future Indigenous women remain under-represented. The findings from this study reinforce that learning from Indigenous women about sexuality and ageing is key to enriching the evidence-base, as well as health worker and researcher capacity, while reinforcing the importance of self-care among Indigenous older women. This project thus promotes a lateral approach to understandings experiences of ageing and sexuality which emphasises cultural plurality. Engaging such an approach with Indigenous women has the potential to increase both the effectiveness and relevance of health promotion and wellbeing programmes aimed at older Indigenous women across generations.

Although this study presents interesting and pre viously undocumented understandings of sexuality and Indigeneity there were some limitations. First all the women identified as Aboriginal. As such, the perspectives of Torres Strait Islander women may not have been captured. Future research with Torres Strait Islander women would give a more robust understanding of Indigenous women's constructions of sexuality.

Also, the majority of the participants were well-educated and many were health care workers. This may have increased their exposure to how others navigate relationships and sexual health/wellbeing via patient/client interaction. As such the sample is not representative of all ageing Indigenous women especially those who may not have high levels of education, or high levels of English literacy to attain high level employment. For those unlike the women in this research difficulty navigating health and wellbeing systems, which are Eurocentric and/or contrary to their epistemological standpoint, may also limit agency in establishing sexual wellbeing.

Although these women were generally well-educated and engaged in professional employment this should not undermine the role and influence of many Indigenous women as formal and informal leaders. Such roles include being influencers, informal decision-makers, and initiators of projects to improve the lives of their families and communities (NSW Health 2013) It would therefore be a mistake to define these women by their educational or professional status. Forthcoming publications take a closer look at the roles Indigenous women play in the context of gender and Indigeneity may illuminate the ways in which ageing Indigenous women support the development and resilience of younger generations.

\section{Acknowledgements}

The authors would like to acknowledge the University of New England for providing the funding necessary to embark on this research through a Partnerships Career Development Awards for Post-Doctoral Fellows/Early Career Researchers awarded to the first author. The research howe ver could not have been done without the active engagement of Family Planning Queensland (second author) and North Coast Aboriginal Corporation for Community Health (third author) who assisted in the recruitment of participants, preparing all materials used for data collection, managing the logistics of the focus groups and supporting the dissemination of this research. We also thank the women in Queensland who provided their time and voices to this project which would not have been possible without their candor during data collection and trust in the aims and goals of the research.

\section{References}

Aniekwu, N. I. (2006). Converging constructions: A historical perspective on sexuality and feminism in post-colonial Africa. African sociological review, 10(1), 143-160.

Bass, E., \& Davis, L. (2002). The courage to heal: A guide for women survivors of child sexual abuse, Random House.

Baxi, P. (2014). Sexual Violence and Its Discontents. Annual Review of Anthropology, 43, 139-154. 
https://doi.org/10.1146/annurev-anthro-102313-030247

Bell, E. L. E., \& Nkomo, S. M. (1998). Armoring: Learning to withstand racial oppression. Journal of Comparative Family Studies, 285-295.

Benzies, K. M. (2014). Parenting in Canadian aboriginal cultures. Parenting Across Cultures, Springer, 379-392. https://doi.org/10.1007/978-94-007-7503-9_28

Berthelot, N., N. Godbout, M., Hébert, M. G., \& Bergeron, S. (2014). Prevalence and correlates of childhood sexual abuse in adults consulting for sexual problems. Journal of sex \& marital therapy, 40(5), 434-443. https://doi.org/10.1080/0092623X.2013.772548

Bessarab, D., \& Ng'andu, B. (2010). Yarning about yarning as a legitimate method in Indigenous research. International Journal of Critical Indigenous Studies, 3(1), 37-50.

Campbell, S., \& Brown, S. (2004). Maternity care with the women's business service at the Mildura Aboriginal Health Service. Australian and New Zealand journal of public health, 28(4), 376-382. https://doi.org/10.1111/j.1467-842X.2004.tb00447.x

Chao, J. K., Y. C., Lin, M. C., Ma, C. J., Lai, Y. C., Ku, W. H. K., \& Chao, I. C. (2011). Relationship among sexual desire, sexual satisfaction, and quality of life in middle-aged and older adults. Journal of sex \& marital therapy, 37(5), 386-403. https://doi.org/10.1080/0092623X.2011.607051

Chesters, J. (2012). Gender attitudes and housework: Trends over time in Australia. Journal of Comparative Family Studies, 511-526.

Cunningham, J., \& Paradies, Y. C. (2012). Socio-demographic factors and psychological distress in Indigenous and non-Indigenous Australian adults aged 18-64 years: analysis of national survey data. BMC Public Health, 12, 95. https://doi.org/10.1186/1471-2458-12-95

Dean, C. (2010). A yarning place in narrative histories. History of Education Review, 39(2), 6-13. https://doi.org/10.1108/08198691201000005

Dockery, A. M. (2010). Culture and wellbeing: The case of Indigenous Australians. Social Indicators Research, 99(2), 315-332. https://doi.org/10.1007/s11205-010-9582-y

Dudgeon, P., \& Hirvonen, T. (2014). Dark chapters in Australian history: Adopted children from the Stolen Generations. InPsych: The Bulletin of the Australian Psychological Society Ltd, 36(4), 12.

Dune, T. (2011). Making sense of sex with people with cerebral palsy.

Dune, T. (2012). Understanding experiences of sexuality with cerebral palsy through sexual script theory. International Journal of Social Science Studies, 1(1), 1-12. https://doi.org/10.11114/ijsss.vli1.6

Dune, T. (2014). Sexuality in chronic illness and disability. Chronic Illness and Disability: Principles for Nursing Practice A. Johnson and E. Chang. Milton, John Wiley \& Sons Australia, 115-132.

Dune, T., \& Mapedzahama, V. (under review). Culture Clash: Shona-Zimbabwean migrant women's experiences with communicating about sexual health and wellbeing across cultures and generations. BMC Public Health. https://doi.org/10.29063/ajrh2017/v21i1.1

Dune, T., V. Mapedzahama, G., Hawkes, V. M., \& Pitts, M. (2015). African Migrant Women's Understanding and Construction of Sexuality in Australia. Advances in Social Sciences Research Journal, 2(2). https://doi.org/10.14738/assrj.22.830

Durex. (2015). Sexual Wellbeing Global Survey 07/08. Retrieved May 8, 2016, from http://www.durex.com/en-lv/sexualwellbeingsurvey/pages/default.aspx

Evans, D. T. (2013). Promoting sexual health and wellbeing: the role of the nurse. Nursing Standard, 28(10), 53-57. https://doi.org/10.7748/ns2013.11.28.10.53.e7654

Fileborn, B., Thorpe, R., Hawkes, G., Minichiello, V., Pitts, M., \& Dune, T. (2015). Sex, desire and pleasure: considering the experiences of older Australian women. Sexual and Relationship Therapy, 30(1), 117-130. https://doi.org/10.1080/14681994.2014.936722

Johnson, K. L., S. Gill, V. R., \& Tassinary, L. G. (2007). Swagger, sway, and sexuality: Judging sexual orientation from body motion and morphology. Journal of Personality and Social Psychology, 93(3), 321-334. https://doi.org/10.1037/0022-3514.93.3.321

Jones, R. K., \& Biddlecom, A. E. (2011). Is the internet filling the sexual health information gap for teens? An exploratory study. Journal of health communication, 16(2), 112-123. https://doi.org/10.1080/10810730.2010.535112

Kalra, G., Subramanyam, A., \& Pinto, C. (2011). Sexuality: Desire, activity and intimacy in the elderly. Indian journal of psychiatry, 53(4), 300. https://doi.org/10.4103/0019-5545.91902 
Kiefer, A. K., \& Sanchez, D. T. (2007). Scripting sexual passivity: A gender role perspective. Personal Relationships 14(2), 269-290. https://doi.org/10.1111/j.1475-6811.2007.00154.x

Kirtz, M. K. (2000). English-Canadian Literary Cultures Observed: Shields' Small Ceremonies and Atwood's LadyOracle. Canada Observed: Perspectives from Abroad andfrom Within, 7, 175.

Landman, M. (2006). Getting quality in qualitative research: A short introduction to feminist methodology and methods. Proceedings of the Nutrition Society, 65(4), 429-433. https://doi.org/10.1079/PNS2006518

Larson, A., M. Gillies, P. J. H., \& Coffin, J. (2007). It's enough to make you sick: the impact of racism on the health of Aboriginal Australians. Australian and New Zealand journal of public health, 31(4), 322-329. https://doi.org/10.1111/j.1753-6405.2007.00079.x

Lindau, S. T., Schumm, L. P., Laumann, E. O., Levinson, W., O'Muircheartaigh, C. A., \& Waite, L. J. (2007). A study of sexuality and health among older adults in the United States. New England Journal of Medicine, 357(8), 762-774. https://doi.org/10.1056/NEJMoa067423

Meston, C. M., Rellini, A. H., \& Heiman, J. R. (2006). Women's history of sexual abuse, their sexuality, and sexual self-schemas. Journal of Consulting and Clinical Psychology, 74(2), 229. https://doi.org/10.1037/0022-006X.74.2.229

Mooney, B., \& Sariago, P. (2015). 2Spirits: Providing a multi-generational, culturally competent approach to health promotion for Aboriginal and Torres Strait Islander communities. HIV Australia, 13(3), 34.

Moreton-Robinson, A. (2003). Researching whiteness: Some reflections from an Indigenous woman's standpoint. Hecate, 29(2), 72 .

NSW Health. (2013). Focus Topic: Aboriginal Women Leaders. from https://www.women.nsw.gov.au/women_in_nsw/current_report/leadership_and_representation/focus_topic_aborig inal_women_leaders

Olesen, V. (2011). Feminist qualitative research in the millennium "s first decade. NK Denzin \& YS Lincoln (2011). The Sage Handbook of Qualitative Research, 129-146.

Orth, U., \& Robins, R. W. (2014). The de velopment of self-esteem. Current Directions in Psychological Science, 23(5), 381-387. https://doi.org/10.1177/0963721414547414

Paradies, Y., \& Cunningham, J. (2009). Experiences of racism among urban Indigenous Australians: Findings from the DRUID study. Ethnic and racial studies, 32(3), 548-573. https://doi.org/10.1080/01419870802065234

Ratner, E. S., Erekson, E. A., Minkin, M. J., \& Foran-Tuller, K. A. (2011). Sexual satisfaction in the elderly female population: A special focus on women with gynecologic pathology. Maturitas, 70(3), 210-215. https://doi.org/10.1016/j.maturitas.2011.07.015

Rheaume, C., \& Mitty, E. (2008). Sexuality and intimacy in older adults. Geriatric Nursing, 29(5), 342-349. https://doi.org/10.1016/j.gerinurse.2008.08.004

Rosengarten, A., \& Simpson, G. (2014). Sex-ability: sex, illness, and disability. Sexual Health: A multidisciplinary approach, 288.

Sandberg, L. (2013). Just feeling a naked body close to you: Men, sexuality and intimacy in later life. Sexualities, 16(3-4), 261-282. https://doi.org/10.1177/1363460713481726

Simon, W., \& Gagnon, J. H. (2011). Sexual conduct: The social sources of human sexuality, Transaction Publishers.

Stavropoulou, A., Kaba, E., Obamwonyi, V. A., Adeosun, I., Rovithis, M., \& Zidianakis, Z. (2012). Defining nursing intimacy: Nurses' perceptions of intimacy. Health Science Journal, 6(3), 479-495.

Ward, J., Bryant, J., Wand, H., Pitts, M., Smith, A., Delaney-Thiele, D., ... \& Kaldor, J. (2014). Sexual health and relationships in young Aboriginal and Torres Strait Islander people: results from the first national study assessing knowledge, risk practices and health service use in relation to sexually transmitted infections and blood borne viruses: The Goanna Survey. Baker IDI Heart and Diabetes Institute Alice Springs. July 2014.

Waters, M. (2013). Nurturing the "beginning" in protecting our traditional practices from the end: family, kinship and Kamilaroi Aboriginal First Nation knowledge in Australia.

\section{Copyrights}

Copyright for this article is retained by the author(s), with first publication rights granted to the journal.

This is an open-access article distributed under the terms and conditions of the Creative Commons Attribution license which permits unrestricted use, distribution, and reproduction in any medium, provided the original work is properly cited. 